\title{
A importância da Literatura Surda na elaboração cultural do Sujeito Surdo:
}

\section{Achados de uma revisão}

The importance of Deaf Literature in the cultural elaboration of the Deaf Subject: Findings of a review

La importancia de la literatura para sordos en la elaboración cultural del sujeto sordo: hallazgos de una revisión

Kaio Germano Sousa da Silva ORCID: https://orcid.org/0000-0003-4236-6230 Faculdade do Vale Elvira Dayrell, Brasil E-mail: kaiogsds@hotmail.com

Cristiane Dutra do Nascimento ORCID: https://orcid.org/0000-0002-8563-6547 Centro Universitário Leonardo da Vinci, Brasil

E-mail: cdncristie.tjls@ hotmail.com

Dácio Machado Teixeira Neto

ORCID: https://orcid.org/0000-0002-6480-5970 Centro Universitário Leonardo da Vinci, Brasil

E-mail: daciomachado6@gmail.com Jânio Oliveira Lima

ORCID: https://orcid.org/0000-0002-9489-6607

Universidade Estadual do Maranhão, Brasil E-mail: janio_jol@hotmail.com Eduardo Brito da Silva

ORCID: https://orcid.org/0000-0002-8571-7806 Centro Universitário de Ciências e Tecnologia do Maranhão, Brasil

E-mail: eduzinhobds@gmail.com

Solange Gonçalves Nunes de Sousa ORCID: https://orcid.org/0000-0003-4327-9323

Universidade Estadual do Maranhão, Brasil E-mail: Solange.nunes_@hotmail.com

Simone Neves Queiroz de Freitas ORCID: https://orcid.org/0000-0002-7295-4511 Universidade Federal do Piauí, Brasil E-mail: simonenqfreitas@hotmail.com

Conceição de Maria Machado Costa Primo ORCID: https://orcid.org/0000-0002-0837-2314 Universidade Estadual do Piaú, Brasil E-mail: mara.con6ao@ hotmail.com

Luana Pereira Ibiapina Coêlho ORCID: https://orcid.org/0000-0002-2054-959X

Universidade Estadual do Maranhão, Brasil E-mail: luana_ibiapina@hotmail.com

Bruna Rafaelle Pereira Ibiapina Coêlho ORCID: https://orcid.org/0000-0002-3122-4803

Escola de Saúde Pública do Ceará, Brasil E-mail: bruna.ibiapina@ hotmail.com

Eudilene da Silva Mesquita ORCID: https://orcid.org/0000-0001-9894-0903 Centro Universitário de Ciências e Tecnologia do Maranhão, Brasil E-mail: eu.mesquitta@gmail.com

Twanny Tachira e Silva Morais ORCID: https://orcid.org/0000-0003-1168-5933

Universidade Estadual do Maranhão, Brasil E-mail: twannynha@hotmail.com

Hidra Santana e Silva Morais ORCID: https://orcid.org/0000-0002-0811-5422

Universidade Anhanguera, Brasil

E-mail: hidra.s.morais@gmail.com 


\author{
Jurlene Ferreira de Queiroz \\ ORCID: https://orcid.org/0000-0001-9922-4968 \\ Universidade Estadual do Maranhão, Brasil \\ E-mail: jurlenequeiroz@gmail.com \\ Adailza Lacerda e Silva \\ ORCID: https://orcid.org/0000-0001-8662-118X \\ Centro Universitário Leonardo Da Vinci, Brasil \\ E-mail: lacerdaadailza1@gmail.com \\ Crislane Morais da Silva Sousa \\ ORCID: https://orcid.org/0000-0003-3647-6214 \\ Universidade Federal do Piauí, Brasil \\ E-mail: crislanelibrastisl@ufpi.edu.br \\ Ranna Johara da Cunha Bacelar de Oliveira Sousa \\ ORCID: https://orcid.org/0000-0001-9373-2304 \\ Centro Universitário Leonardo Da Vinci, Brasil \\ E-mail: rannajoharab79@gmail.com \\ Ana Larissa Cardoso Silva Rocha \\ ORCID: https://orcid.org/0000-0002-3014-1029 \\ Instituto de Ensino Superior Múltiplo, Brasil \\ E-mail: analarissacss@ hotmail.com \\ Saleia Soares Leitão Silva \\ ORCID: https://orcid.org/0000-0001-8627-3680 \\ Universidade Federal do Piauí, Brasil \\ E-mail: saleiasoares@hotmail.com
}

\begin{abstract}
Resumo
A literatura tem sua importância do ponto vista cultural na formação da identidade cultural de Surdos dentro do seu âmbito de convívio social. Nesta perspectiva, o conhecimento da Cultura Surda e sua dinâmica de influência na aquisição da Língua de Sinais, caracteriza em conhecimentos adquiridos, no que se refere aos de cunhos históricos e sociais. Portanto este estudo teve como objetivo apresentar a importância da literatura Surda na elaboração da identidade cultural no sujeito Surdo. Para a realização deste estudo, trabalhou-se uma revisão de literatura narrativa, baseada em uma ampla discussão da produção temático-científica. Deste modo, Literatura Surda é definida como criação de textos sinalizados, que atende o indivíduo Surdo como presença de algo de sua cultura literária, permeando outras caracterizações de surdos, considerando-os como um grupo linguístico e cultural diferente. A Literatura Surda permite não semente o sentido cultural, mas também o sentido educacional e inclusivo. A importância da estratégia da inclusão da Literatura em auxiliar o surdo no sentido de identidade cultural e no aspecto de aquisição de comunicação. O trabalho conseguiu atender o objetivo proposto, destacando que o corpo do trabalho explanou todos os aspectos linguísticos desde a importância da aquisição da Libras, conhecendo sua trajetória e sua influência na identidade cultural surda e como base no caminho literário adaptado. Por fim, percebeu-se ainda a necessidade de estudos com essa temática serem realizados, a fim de investigar a relação da literatura surda e o grau de elaboração de personalidade cultural nestes indivíduos.
\end{abstract}

Palavras-chave: Literatura surda; Identidade cultural; Surdo.

\begin{abstract}
A literature is of the importance of the cultural point of view in the formation of the cultural identity of Surdos within the scope of social coexistence. This perspective, or knowledge of Culture Surda and its dynamics of influence in the acquisition of the Sinais Language, characterizes the knowledge acquired, not that it refers to years of historical and social history. Therefore, this study has the objective of presenting the importance of Surda literature in the elaboration of cultural identity not subject to Surdo. For the realization of this study, we work on a review of narrative literature, based on a wide discussion of thematic-scientific production. In this way, Surda Literature is defined as the creation of texts that are singled out, which serves as an individual Surdo as a presence of some of its literary culture, permeating other characteristics of surdos, considering you as a different linguistic and cultural group. A Surda Literature allows no semente or cultural sense, but also an educational and inclusive sense. Importance of the strategy for the inclusion of Literature in auxiliary or non-sense of cultural identity and not aspect of communication acquisition. Either work managed to meet the proposed objective, highlighting that the body of work explains all linguistic aspects from the importance of the acquisition of Libras, understanding its costume and its influence on cultural identity surda and as a basis not adapted literary path. Finally, percebeu-is added to the necessity of studies on this subject matter that will be carried out, in order to investigate the relationship of literature on the subject and the degree of elaboration of cultural personalities within individuals.
\end{abstract}

Keywords: Surda literature; Cultural identity; Surdo.

\title{
Resumen
}

La literatura tiene su importancia desde el punto de vista cultural en la formación de la identidad cultural de las personas sordas dentro de su ámbito de vida social. En esta perspectiva, el conocimiento de la Cultura Sorda y su dinámica de influencia en la adquisición de la Lengua de Signos, se caracteriza en los conocimientos adquiridos, en 
cuanto a aspectos históricos y sociales. Por tanto, este estudio tuvo como objetivo presentar la importancia de la literatura sorda en la elaboración de la identidad cultural en el sujeto sordo. Para la realización de este estudio se realizó una revisión de la literatura narrativa, a partir de una amplia discusión de la producción temático-científica. Así, la literatura para sordos se define como la creación de textos firmados, que sirve al individuo sordo como la presencia de algo de su cultura literaria, impregnando otras caracterizaciones del sordo, considerándolo como un grupo lingüístico y cultural diferente. La literatura para sordos permite no la semilla de un sentido cultural, sino también un sentido educativo e inclusivo. La importancia de la estrategia de inclusión de la literatura para ayudar a los sordos en el sentido de identidad cultural y en el aspecto de la adquisición de la comunicación. El trabajo logró cumplir con el objetivo propuesto, destacando que el cuerpo de trabajo explicó todos los aspectos lingüísticos desde la importancia de adquirir Libras, conociendo su trayectoria y su influencia en la identidad cultural sorda y como base para el camino literario adaptado. Finalmente, también se advirtió la necesidad de realizar estudios con esta temática, con el fin de indagar en la relación de la literatura sorda y el grado de elaboración de la personalidad cultural en estos individuos.

Palabras clave: Literatura para sordos; Identidad cultural; Sordo.

\section{Introdução}

O presente estudo tem como tema, "A importância da Literatura Surda na elaboração cultural do Sujeito Surdo: Achados de uma revisão". O trabalho vem mostrar a Literatura Surda como ferramenta de elaboração de identidade cultural destes indivíduos. Com isso, busca a compreensão da dinâmica da Libras e sua importância adaptativa nas literaturas ou até mesmo contos e histórias voltados para esse grupo.

Com isso, a avaliação revela que a literatura tem sua importância do ponto vista cultural na formação da identidade cultural de surdos dentro do seu âmbito de convívio social. Nesta perspectiva, o conhecimento da Cultura Surda e sua dinâmica de influência na aquisição da Língua de Sinais, caracteriza em conhecimentos adquiridos, no que se refere aos de cunhos históricos e sociais, com sua conjuntura na formação de profissionais da educação ou também de outras áreas, assim com todos aqueles fazem parte do âmbito social de interação com o surdo, proporcionando um eixo educativo e na formação dos sujeitos surdos e apresentando-lhes que a escola bilíngue é o caminho para proporcionar melhorias nesta modalidade de educação, que de certa forma trabalha a inclusão da cultura dos surdos, sem trabalhar diretamente com a cultura ouvinte, tendo como base a Libras, sua língua materna e que esta é reconhecida e regulamentada por lei (Silva, 2014).

Nessa perspectiva, discutir de forma geral, a cultura da pessoa surda tendo como base a sua literatura como umas das protagonistas na formação cultural na Identidade Surda, com o objetivo de anseio da pesquisa central reparar as problemáticas deste público surdo de forma individual e coletivo em sua inserção e interação com o meio que convive, tornando-a mais acessível, fazendo com que a sociedade de forma geral possa compreender e conhecer a cultura destes sujeitos, como também auxiliar na formação de sua identidade tendo como foco a sua literatura, e claro, fomentar que todos se tornem bilíngues e a surdez passe a ser e percebida não como deficiência, mas uma cultura (Silva et al., 2019).

Para a realização deste estudo, trabalhou-se uma revisão de literatura narrativa, baseada em uma ampla discussão da produção temático-científica, que teve como ponto de partida responder o seguinte questionamento: Como a Literatura Surda contribui na formação cultural da identidade do Surdo? Para obter tal resposta, teve-se como base o seguinte objetivo: Apresentar a importância da Literatura Surda na elaboração da identidade cultural no sujeito Surdo

Para se alcançar tal objetivo e responder à questão citada do presente trabalho, teve-se como base a análise de literaturas disponíveis. A prática tem como base a evidência, tem como objetivo a identificação, através de focos de outras pesquisas, se um método é eficiente para responder a problemática, avaliando a qualidade dos estudos encontrados e mecanismos para a execução na assistência. Envolve como ponto de partida a definição de um problema, a busca e a avaliação analítica dos indicativos disponíveis, trabalhando na implementação das mostras na prática e a avaliação e na qualidade dos resultados encontrados.

A organização do artigo está caracterizada da seguinte forma: uma análise da vivência do Surdo com sua cultura, uma 
explanação dos Aspectos gerais da Literatura Surda e o tópico que traz a finalização da percepção e objetificação da Literatura Surda e sua importância na dinamização de identidade cultural no sujeito Surdo.

A inclusão tem como objetivo atender aos alunos com necessidades especiais que possam dificultar o seu processo de aprendizagem e com isso, diminuir os tabus e justificativas que surgem, e forma da normalização que tem o cuidado de atender às condições para essa total integração seja feita da mais positiva possível, e assim, garantir a participação de todos os alunos na sociedade.

Segundo o pensamento de autores Machado e Prestes (2017) sobre a consonância da cultura Surda e da aquisição de linguagem na elaboração da identidade cultural:

Um surdo estará próximo de criar sua identidade cultural quando criar um aspecto de conversão dentro da sociedade. Por isso, a importância do surdo interagir com outros de seu grupo, formando assim, a construção da aquisição de linguagem através da Língua de Sinais Brasileira - LIBRAS, valorizando seus contextos identificar os seus costumes dentro de comunidade que faz parte, tendo como resultado a intensificação da cultura que faz parte com auxílio da Literatura Surda. Perante isto, as pessoas surdas precisam ter mais contatos com surdos para que sua linguagem se desenvolva principalmente as crianças surdas para adquirir a língua de sinais.

Toda sociedade em vivência, necessita de cultura para elaborar sua identidade. Deste modo, a Cultura Surda tem como umas das características, a aquisição a língua dos surdos, pois o surdo com inserção nesta cultura, terá mais facilidade no seu processo de aprendizado da sua língua de sinais. A escolha do tema surgiu pela curiosidade em descobrir a importância da Literatura Surda na construção da identidade cultural no sujeito surdo, e também como via de mão de contribuir para inclusão destes indivíduos

\section{Metodologia}

Estudos de revisão de são divididos em narrativos, integrativos ou sistemáticos. Trazendo para este trabalho, o mesmo consistiu-se numa pesquisa narrativa com abordagem qualitativa, utilizando uma análise bibliográfica de caráter narrativo realizada através de consulta em bases de dados online de pesquisa: Scielo (Scientific Eletronic Library OnLine), ERIC (Education Resources Information Center) e Google acadêmico (Silva et al., 2021). A pesquisa foi realizada no ano de 2021, com artigos que se encaixava no recorte temporal de 2016 a 2021.

Foram utilizados a os seguintes descritores e suas consonâncias nas línguas portuguesa, espanhola e inglesa: "Literatura Surda 1", "Identidade cultural 2", "Surdo 3". Vocábulos com grau de semelhança foram usados em outras bases de dados. Seguindo o trajeto metodológico, foi identificado 20 artigos de acordo com esses termos usados. Em seguida, fez-se a leitura detalhada, com resultado de 15 artigos, sendo 5 artigos oriundos do Google acadêmico, 2 oriundos da Scielo e 8 oriundos da ERIC.

No que se refere aos critérios de inclusão: Identificação e caracterização do artigo, ano de publicação no recorte temporal (2016 a 2021) e clássicos, artigos fora do recorte temporal de grande relevância, e que tratavam do tema proposta a importância da literatura Surda na elaboração da identidade Surda. Também houve pesquisa em documentos governamentais e foram incluídos os trabalhos que relacionaram a importância da Literatura na formação cultural de sujeitos surdos.

Quanto aos critérios de exclusão, foram excluídos artigos com formato de cartas ao editor, comentários, casos em séries, resumos que não foram publicados, trabalhos que não se adequavam com os objetivos e ao tema proposto em conjunto com os descritores "1", "2", “3”; aqueles que não se enquadravam no recorte temporal supracitados acima, e os que não se apresentavam disponíveis em textos completos. Os artigos foram lidos de forma minuciosa e crítica, e foram selecionados os textos que melhor abordaram o tema. 


\section{Resultados e Discussão}

\section{Língua Brasileira de Sinais (Libras) e cultura surda}

Tendo como ponto de início os movimentos que abrangem os Estudos Culturais em Educação no contexto do indivíduo Surdo, a cultura surda pode ser compreendida como estilo de vida, um meio de construção de identidade e de via de mão, o aspecto interativo com as comunidades que caracterizam o modo de vivência com os sujeitos e o povo surdo (Müller \& Kist, 2020).

Com isso, no modo de entendimento no campo de vivência do surdo pode-se caracterizar como um campo de lutas e conquistas, um espaço que ainda existe conflitos na elaboração da identidade, trazendo para os aspectos culturais os mesmos, ainda existem suas circulações através de fissuras e rachaduras presente na comunidade, com complexidade em seus significados" (Klein \& Lunardi, 2006).

Assim, mesmo diante de um processo de familiarização com a cultura surda, entende-se que a mesma ainda está em constante processo de afirmação, uma vez que mesma não hominizada e tão pouco pura em suas características, isso se dá devido a individualidade de cada sujeito, pois cada um tem suas especificidades, não podendo uniformizar o estilo de vida devido as particularidades, a cultura Surda e firmada em trajetórias de ressignificações (Silva et al., 2019).

Fazendo a retrospectiva da trajetória da Libras, Dom Pedro II teve anseio de trazer a Língua de Sinais para o Brasil, tendo como principal motivo a educação do seu neto surdo, filho de princesa Isabel, pois o imperador visava alfabetizá-lo. Com isso, convidou o professor francês Ernest Huet, precursor da Língua de sinais francesa e também da brasileira. Ernest era surdo, aluno do Instituto Parisiense e criador do alfabeto manual francês (Silva et al., 2019).

Ao chegar, o professor Ernest presenciou uma educação totalmente defasada com vários problemas tantos estruturais como no processo educativo de alunos surdos. Foi então que teve a ideia de solicitar ao imperador um prédio, na tentativa de organizar o ensino, e foi na data de 26 de setembro de 1857, que surgiu o Instituto Nacional de Educação do Surdo que na época levava o nome de o Instituto dos Surdos-Mudos do estado do Rio de Janeiro (Honora, 2019).

Sabendo das conquistas do processo cultural da identidade do surdo, tendo a Libras como principal conquista na aquisição da linguagem e da comunicação, no ano 1911 essa sofreu um grande retrocesso, analisando o contexto de Silva et al. (2019):

O Instituto de educação do Surdo (INES) em 1911, devido ao Congresso Nacional dos Surdos e Mudos de Milão, passou a adotar a metodologia de ensino o oralismo puro como linguagem primário e a de sinais passou a ser secundara, tendo como argumentação que a criança teria uma acomodação em aprender somente a linguagem de sinais, com isso a libras passou a ser uma subcultura.

Ao estudar esse tipo de consciência de luta e preconceito, os direitos dos surdos no campo da educação valorizam sua trajetória. A luta pelos direitos desse grupo começou a ganhar força, de modo que em 1923, foi criada uma escola particular no Estado de São Paulo só para o público feminino, a escola se chama Instituto Santa Terezinha, outra conquista foi a escola de Vitória - Espírito Santo, para atender as necessidades e alfabetizar surdos e mudos, fundada na data de 1957 (Felipe, 1997).

Voltando para cultura surda, "O surdo" é aqui entendido como "um sujeito com linguagem, cultura e identidades múltiplas, um sujeito diferente da construção social e política” (Lunardi-Lazzarin \& Morais, 2009). A Cultura Surda se manifesta principalmente na Libras, associações, escola, família e outros âmbitos de inserção do mesmo. Tais áreas podem ser divididas em âmbito social, cultural e educacional, representando a multifacetada identidade do surdo.

Neste aspecto, a Literatura Surda tem sua importância, na elaboração da identidade cultural surda, possibilitando que o mesmo tenha em seu processo de ensino a aquisição da Língua de Sinais, pois são os textos voltados e adaptados para esse grupo que possibilitam a estes indivíduos o conhecimento do mundo literário surdo e também o do ouvinte. Neste aspecto, a 
difusão da cultura surda é ligada à Libras e a Literatura voltada a estes indivíduos (La taille, 2019).

A Literatura Surda permite não somente o sentido cultural, mas também o sentido educacional e inclusivo. A importância da estratégia da inclusão da literatura ao auxiliar o surdo no sentido de identidade cultural e no aspecto de aquisição de comunicação. Deste modo, Karnopp (2006) define que Literatura Surda "é a criação de textos sinalizados, que atendem o indivíduo surdo como presença de algo de sua cultura literária, permeando outras caracterizações de surdos, considerando-os como um grupo linguístico e cultural diferente".

Enfim, os surdos também são considerados sujeitos com diversificação de faces em várias áreas, sua existência e vivência no mundo são coletivas (no encontro com outras pessoas surdas ou não) e sentidas de forma única. De maneira geral, o sujeito sente-se compreendido e pertencente a uma nação ou grupo, na ordem dos eventos culturais, ou seja, na ordem de se tornar, de vir a ser e de enfrentar a luta permanente de outras pessoas e as suas próprias. (López \& Veiga-Neto, 2010).

\section{Aspectos gerais da Literatura Surda}

Entende-se que a cultura surda abrange caraterísticas como o fato de ser transmitida em língua gestual, e pode ser passada de pais para filhos, de geração para geração. A partir daí essa "herança" vem acompanhada de valores, costumes, familiarização com sua história, e expressão da sua arte, por meio de contos, poesia, teatro e narrativas de experiências.

De acordo com Ben Bahan (2006), a Cultura Surda é o resultado da experiência surda do mundo associado ao conhecimento do mundo em geral. Suas experiências pessoais e visuais e têm influência sobre seus interesses, suas ideias e sua arte.

Reconhecida como artefato cultural, a Literatura surda, é muito aceita, na comunidade surda, pois abrange por meio de imagens, dança, dramatização, músicas, poemas e narrativas pessoais, as experiências do público surdo. Assim, possibilita um despertar no sujeito que, já passou pelas mesmas experiências, que tem os mesmos desafios, a superar-se.

Os temas de expressão são muito relevantes, a saber: resistência à opressão, pela sociedade ouvintista, desafios encontrados na educação dos surdos, o despertar para a sua língua natural - Libras, os movimentos e conquistas pela luta em prol dos direitos da comunidade surda (Schlemper, 2016).

Para que seja possível a análise da forma de um texto literário em Libras, o grupo holandês ECHO, em consonância com Sutton-Spencer (2021), publicaram sugestões de elementos linguísticos que favorecem a compreensão de sinais e trechos de sinais, são eles: a glosa do sinal (geralmente um para cada mão); repetições do sinal (em que "x" representa que há repetições e é acompanhado pelo número da quantidade de tais repetições); direcionamento dos movimentos de locação do sinal (geralmente indicando pela letra inicial segundo a direção e o ângulo correspondente); movimento da cabeça; posição das sobrancelhas; abertura dos olhos; direcionamento do olhar; movimentos da boca; papel do ator (personagem ou narrador); observações e anotações (não raro são vistos mais detalhes a cada repetição); tradução.

Portanto, o ensino de literatura na escola promove a formação do senso de identidade e do interesse pela leitura dos públicos, tanto de alunos ouvintes como de alunos surdos. Quanto mais cedo forem expostos a histórias, poemas, contos, fábulas, piadas e outros textos, maior será a probabilidade de desenvolverem o gosto pela leitura de símbolos em sua linguagem. Além disso, as obras literárias têm um impacto positivo na identidade das crianças surdas. Muitos surdos se julgam inferiores aos ouvintes, mas quando percebem que há obras em sua língua, percebem que não são inferiores, apenas usam uma linguagem diferente (Laboritt, 1994).

Enfim, a luta por mais direitos deve ser continua entre a comunidade surda em busca de melhorias, na área da educação e áreas afins, é imensamente importante, esta luta se embasar nesse sentido de melhorar o sistema, como forma de garantir qualidade de vida e uma valorização da cultura surda, nada está adaptado só está se garantido o que é previsto em lei, a muito que ainda deve ser feito como, libras nos currículos de todos, libras na literatura de todas as grandes curriculares e ter 
mais representatividade no sentido cultural e literário nas adaptações para o surdo.

\section{Literatura surda e sua importância na dinamização da identidade cultural no sujeito surdo}

Surdos se reúnem constantemente para contar histórias e trocar suas convivências; as modalidades de contação de histórias, estão os relatos de vida, piadas e aquelas que incluem aspectos da cultura surda, com personificação de pessoas surdas. São narrações, que de forma em geral, têm o envolvimento nas diversificações entre o mundo surdo com do ouvinte (Karnopp, 2010; Karnopp,2013).

Durante séculos, vários foram os percalços que a comunidade surda teve que enfrentar para que a sua cultura fosse realmente reconhecida. Atualmente, os sujeitos surdos podem expressar seus pensamentos, e o melhor, narrar suas histórias de vidas, que podem ser recontadas de geração a geração. Essas narrativas são expressas através da Língua de Sinais, sendo assim, um marcador identitário da comunidade surda (Walsh, 2017).

A Literatura Surda tem sua importância, ou seja, um valor cultural entre os povos surdos, pois a sua base está interligada entre os sujeitos, sua língua e principalmente sua identidade, onde através das experiências partilhadas, podem construir sua cultura, como também narrar fatos e, ao mesmo tempo, adaptar para o seu contexto as produções existentes na Literatura ouvinte, passando a integrar essas produções ao artefato cultural dos povos Surdos (Woordward, 2000).

Relembrando as palavras de Strobel, (2018), a Literatura Surda tem como referências em seus aspectos, a variedade de experiências individuais da comunidade surda. Onde estes, em determinadas vezes, narram os obstáculos e vitórias em cima da opressão dos ouvintes, diante de muitas dificuldades que surgiram na elaboração da sua identidade cultural, até mesmo na aquisição da linguagem, testemunhando relatos de personagens, que serviram de incitativo de empoderamento da cultura do sujeito com surdez.

Deste modo, a formação da identidade cultural do indivíduo surdo é possível por meio da aquisição não somente da língua, mas também através da literatura, pois através dela a mesma, permite-se a ocorrência da elaboração de identificação cultural do povo surdo que convive com sua literatura. Como afirma Karnopp (2008), a Literatura Surda permite novas representações para o povo surdo e afirmação de uma identidade positiva com indivíduo surdo.

Nesse sentido, para Da Silva, Hall e Woodward (2014), a literatura surda tem sua representação da inclusão de práticas de significação e sistemas simbólicos de quais a definição de sinais é estabelecida, dependendo do posicionamento do sujeito. É por meio dos significados elaborados que caracteriza os indivíduos no seu modo de agir, pensar e no seu eu[...] Os diálogos e a sistematização de representação ajudam na construção de onde os indivíduos têm a capacidade de se posicionar dentro do seu lugar de fala [...].

Sendo a representação da elaboração da identidade cultural conquistada através da literatura surda, sua significância na contextualização da inserção do indivíduo surdo em entrar em contato com as relações de poder em relação aos ouvintes. Tal processo tem como objetivo a identificação dos valores de cunho linguístico-culturais em sujeitos com surdez tendo como base a literatura em seu reconhecimento de convivência com todos que o cerca (Silva et al., 2019).

Segundo Carvalho, Duarte, Menezes e Souza (2019) “[...] a cultura tem influência no molde ao criar o sentido as experiências, facilita o processo entre as conivências entre várias identidades [...]". A experiência atribuída com a Literatura Surda, permite ao surdo um espaço de trocas de experiências e vivências dando um contexto literário de significado e ressignificação de seus valores e costumes, por meio e tal elaboração, identifica e resulta no encaixamento social. As diferenças de cultura surda e ouvinte, assim como a importância das mesmas contribui na formação da identidade do sujeito surdo.

A Literatura Surda, nesse contexto, é fortalecida como artefato construtor de identidade do surdo, pois em suas produções culturais, os valores linguístico-culturais que constituem a identidade do povo surdo (língua de sinais, experiências 
visuais, contato com a comunidade surda, dentre outros), estão associadas à construção de suas produções, de forma que, artefato literatura surda e desenvolvimento da identidade estão associados (Viana, 2021).

Dentro do contexto escolar, Pissinatti et al. (2020), opinam sobre a importância da Literatura Surda em sala de aula:

O contato com a literatura surda em sala de aula, permite ao aluno surdo, empoderar-se; 5/7 dos valores linguísticoculturais do seu povo, desenvolvendo sua identidade por meio de um movimento de identificação com as representações da obra, porém, não basta somente ter contato, o professor precisa intervir de forma mediadora nesse processo. O aluno não realiza o processo descolonizador de valores ouvintistas de maneira solitária. O professor, nesse sentido, é fundamental criando estratégias de intervenção e problematização para que o surdo consiga significar e re-significar, encontrando-se a si mesmo e às diferenças por meio das produções literárias de sua comunidade. Intervir com a literatura surda na sala de aula, por meio de estratégias diversas faz dessa ação uma pedagogia descolonizadora confrontando o aluno, tanto surdo como também ouvinte, com seus valores e diferenças.

Nesta perspectiva, o pensamento gerador é o fortalecimento no desenvolvimento da identidade individual e contribuindo para interação coletiva, pois em tais narrações de cunho linguístico ligadas com os aspectos culturais destes indivíduos, o surdo passa a ser um indivíduo ativo. Assim, a Literatura Surda tem como finalidade apresentar a luta pela valorização dos movimentos surdos, na expressão de sua arte, no seu contato com a Língua de Sinais. Daí a grande importância do docente que cria um espaço no seu âmbito educacional que visa combater posturas que vão contra a ética e contra preconceitos, tornando possível o combate de enfretamento às práticas que não respeita as diferenças.

Portanto, a Literatura Surda é capaz de viabilizar o processo de aquisição da identidade surda, onde os sujeitos passarão a valorizar sua cultura como também, terão um melhor desempenho no processo ensino- aprendizagem da L1(Libras) e posteriormente a L2( Português Escrito), sendo que o contato precoce com o mundo literário poderá abrir novos horizontes, se tratando do desenvolvimento social, o mesmo saberá questionar e lutar pelo processo de inclusão dos seus pares, como também pela valorização de sua cultura (Cosson, 2016).

\section{Conclusão}

O estudo trouxe reflexões importantes sobre a importância da Literatura Surda na idealização cultural no sujeito surdo. Foi possível observar o quanto esta aquisição influencia diretamente no molde identificatório cultural no sujeito com surdez, e como essa, através das adaptações ou produções surdas, têm influências diretas na comunicação, interação educacional e social.

O trabalho conseguiu atender o objetivo proposto, destacando que o corpo do trabalho explanou todos os aspectos linguísticos desde a importância da aquisição da Libras, conhecendo sua trajetória e sua influência na identidade cultural surda e como base no caminho literário adaptado para surdo e sua importância na elaboração do sentido de erudição neste grupo e como também fortalecimento dos aspectos culturais nestes indivíduos.

Evidenciou-se que a Literatura Surda não contribui somente para elaboração cultural no sujeito surdo, mas também é uma técnica que permeia a facilitação do ensino e aprendizagem dos mesmos. Com isso, faz - se necessário que este tema possa ter maior extensão no campo educacional e social, como uma estratégia complementar ao ensino inclusivo e aquisitivo de linguagem e comunicação. Contudo, as narrações surdas não vêm somente caracterizar culturalmente o surdo, elas também dão suporte ao professor no processo de desenvolvimento cognitivo dos alunos surdos ou não, essa estratégia preconiza um olhar dinâmico motivador que contribui na socialização nas metodologias e adaptações curriculares do ensino como um todo, tornando o saber mais atrativo.

Este estudo provém dos estímulos de cunho cientifico e metodológico e será útil aos profissionais que atuam na áreas da educação e afins, facilitando a compreensão do contexto laboral da Literatura Surda como objeto que proporciona 
identidade cultural a sujeitos surdos, além de relacionar a prática da mesma como técnica auxiliadora na busca de aquisições linguísticas, e da sua importância para o aprendizado e fomentação de fortalecimentos das interações sociais no contexto escolar, cultural e social. Por fim, a necessidade de estudos com essa temática serem realizados a fim de investigar a relação da Literatura Surda e o grau de elaboração de personalidade cultural nestes indivíduos.

\section{Referências}

Bahan, B. (2006). Face to face tradition in the American Deaf Community in H-Dirksen. In: N. J. Bauman \& H. Rose (Orgs.). Signing the Body Poetic (pp.2150). California: University of California Press.

Carvalho, L. O. R., Duarte, F. R., Menezes, A. H. N., \& Souza, T. E. S. (2019). Metodologia científica: teoria e aplicação na educação a distância. Petrolina: Fundação Universidade Federal do Vale do São Francisco.

Cosson, R. (2016). Letramento literário teoria e prática. Contexto.

Felipe, T, A. (1997). Introdução à Gramática da LIBRAS. In: G. Rinaldi et al. (Orgs.). Educação Especial Deficiência Auditiva. Brasília: Ministério da Educação.

Honora, M. (2019). Livro Ilustrado de Lingua Brasileira de Sinais. Ciranda Cultural.

Karnopp, L. B. (2013). Produções culturais em língua brasileira de sinais (Libras). Letras de Hoje, Porto Alegre, 48(3), 407-413.

Karnopp, L. B. (2010). Produções culturais de surdos: análise da literatura surda. Cadernos de Educação, 36, 155-174.

Karnopp, L.B., \& Machado, R. (2008). Literatura surda: ver histórias em língua de sinais. Anais do Seminário Brasileiro de Estudos Culturais em Educação $(C D)$ - 2SBECE, Canoas, RS, Brasil.

Karnopp, L. B. (2006). Literatura, Letramento e Práticas Educacionais Grupo de Estudos e Subjetividade. Educação Temática Digital, 7(2), 98-109.

Klein, M., Lunardi, M. L. (2006). Surdez: um território de fronteiras. EDT: Educação Temática Digital, 7(2), 14-23.

Laboritt, E. (1994). O voo da gaivota. Best Seller.

La Taille, Y. L. (2019). Piaget, Vygotsky, Wallon: teorias psicogenéticas em discussão. Summus.

López, M. C., Veiga-Neto, A. (2010). Marcadores Culturais Surdos. In: L. M. C. Vieira-Machado, M. C. Lopes (Orgs.). Educação de Surdos: políticas, língua de sinais, comunidade e cultura surda. Santa Cruz do Sul: EDUNISC.

Machado, F. M. A., \& Prestes, G. R. L. (2017). LIBRAS - Língua Brasileira de Sinais. Caxias do Sul: Educs.

Lunardi-Lazzarin, M. L. \& Morais, M. Z. (2009). Pedagogia e diferença: capturas e resistências nos discursos curriculares da educação de surdos. In: A. S. Thoma \& M. Klein (Orgs.). Currículo \& avaliação: a diferença surda na escola. Santa Cruz do Sul: EDUNISC.

Müller, J. I., \& Kist, K. (2020). Língua Brasileira de Sinais e cultura surda: práticas inclusivas em um Instituto Federal. LÍNGUATEC, 5, 62-74.

Pissinatti, L. G., Mori, N. N. R. (2020). Literatura surda na região amazônica: o ambiente educacional como espaço da construção da identidade a partir da experiência estética. Série-Estudos - Periódico do Programa de Pós-Graduação em Educação da Ucdb, 25(54), 117-132.

Schlemper, M. (2016). Traduções infantis para Libras: o conto como mediador de aquisição sinalar (Dissertação de mestrado). Universidade Federal de Santa Catarina, Florianópolis, SC, Brasil.

Da Silva, T. T. (2014). A Produção Social da Identidade e da Diferença. In: T. T. da Silva, S. Hall, \& K. Woordward (Org.). Identidade e Diferença: a perspectiva dos Estudos Culturais (15a ed., pp. 73-101). Vozes.

Silva, K. G. S., Morais, E. R. O., Silva, F. T. S. E., Medeiros, S. B. M., \& Morais, T. O. (2019). A inclusão do surdo e deficiente auditivo no âmbito educacional: uma revisão. Anais Do I Seminário Mãos que Comunica, Caxias, MA, Brasil, p.36-45.

Silva, K. G. S., Silva, A. L. E., Teixeira Neto, D. M., Guimaraes, M. J. A., Coutinho, M. N. F., \& Lima, J. O. (2019). O contexto social do surdo: conhecendo a inserção deste nos seus diversos âmbito. Anais Do I Seminário Mãos que Comunica, Caxias, MA, Brasil, p.46-51.

Silva, K. G. S., Cunha, A. H. S., Primo, C. M. M. C., \& Nascimento, C. D. (2019). A intermediação alfabetizadora com o intérprete de libras. Anais Do I Seminário Mãos que Comunica, Caxias, MA, Brasil, p.52-58.

Silva, K. G. S., Silva, A. L. E., Teixeira Neto, D. M., Guimaraes, M. J. A., Coutinho, M. N. F., \& Lima, J. O. (2019). Libras no contexto educacional: uma revisão literária na contemporaneidade. Anais Do I Seminário Mãos que Comunica, Caxias, MA, Brasil, p.59-67.

Silva, K. G. S., Santos, N. L. C., Silva, F. T. S., Sousa, S. G. N., Nascimento, C. D., Primo, C. M. M. C., \& Melo, K. C. (2021). Affectivity as a methodological practice in children's education: A narrative review. Research, Society and Development, 10(4), e36410414053.

Silva, K. G. S., Melo, K. C., Santos, M. E. L. C., Silva, A. T., Lima, A. S. S., Pessoa, N. M., \& Morais, T. O. (2021). Functional properties of babassu coconut mesocarp flour: a nutritional alternative against Covid-19. Research, Society and Development, 10(2), e58010212851. 
Research, Society and Development, v. 10, n. 8, e59610817954, 2021

(CC BY 4.0) | ISSN 2525-3409 | DOI: http://dx.doi.org/10.33448/rsd-v10i8.17954

Sutton-Spence, R. (2021). Literatura em Libras. Arara Azul.

Strobel, K. (2018). As imagens do outro sobre a cultura surda. (5a ed.). Editora da UFSC.

Viana, J. M., \& Lebedeff, T. B. (2021). O sistema Shape Coding como ferramenta para a reflexão linguística em Língua Portuguesa para surdos. In: R. A. F. Da Silva, M. Hollosi, (Org.). Educação de surdos, linguagens e experiências (1a ed., pp. 166-181). Editora Navegando.

Walsh, C. (2017). Gritos, grietas y siembras de vida: Entretejeres de lo pedagógico y lo decolonial. In: C. Walsh (Org,), Pedagogías decoloniales: prácticas insurgentes de resistir, (re)existir y (re)vivir (pp. 17-49). Quito-Equador: Ediciones Abya Yala, 2017.

Woordward, K. (2000). Identidade e diferença: uma introdução teórica e conceitual. In: T. T. Silva (Orgs.), Identidade e diferença: a perspectiva dos estudos culturais (12a ed., pp. 7-84). Vozes.

Da Silva, T. T., Hall, S., \& Woodward, K. (2014). Identidade e diferença: a perspectiva dos Estudos Culturais. (15a ed.). Vozes. 